\title{
The Effect of Vanilla Extract on the Comfort Level of Neonates When Taking Venous Blood
}

\section{Reni IImiasih and Juwitasari Juwitasari”}

Diploma Degree of Nursing, Faculty of Health Science, University of Muhammadiyah Malang, Indonesia

\section{ORCID}

Juwitasari Juwitasari: https://orcid.org/0000-0001-9161-091X

\begin{abstract}
Taking venous blood in neonates can be challenging. The discomfort felt when taking blood can cause difficulties or even failure in carrying out the procedure, so that the venous blood collection must be repeated in another collection area. The repetition of the procedure has a negative impact on neonates, such as impaired psychological aspects and behavioral development. Vanilla extract has a similar aroma as the mother's breast milk and so it was hypothesized that it could help provide comfort for neonates. This study described the characteristics of newborns, classified the degree of their disease, then determined the comfort level and pain level after taking venous blood. This cross-sectional study of 36 hospitalized neonates took place from October 1st - November 28th, 2020, in the perinatology room of University of Muhammadiyah Malang Hospital. The characteristics data were collected from the nursing charts, the level of pain was analyzed based on the Neonatal Infant Pain Scale and the comfort level was determined using a comfort scale. More than half of the newborns (64\%) were one day old, and 19 newborns were female. The most severe level of disease was categorized as level 1 (28 newborns) which was diagnosed as premature rupture of membranes and umbilical cord infection. The level of pain identified in the 36 neonates had an average value of $4.94 \pm 0.71$. The average level of comfort in neonates when taking venous blood was $22.5 \pm 3.41$.
\end{abstract}

Corresponding Author:

Juwitasari Juwitasari; email:

juwita@umm.ac.id

Published: 7 February 2022

Publishing services provided by Knowledge E

(c) Reni IImiasih and Juwitasari Juwitasari. This article is distributed under the terms of the Creative Commons

Attribution License, which permits unrestricted use and redistribution provided that the original author and source are credited.

Selection and Peer-review under the responsibility of the IVCN Conference Committee.
G OPEN ACCESS
Keywords: comfort, pain, vanilla, newborns

\section{Introduction}

The discomfort during the procedure for taking venous blood was also felt by neonates [1]. Venous blood sampling is a routine invasive procedure performed on neonates who are hospitalized [2]. Neonates are particularly vulnerable to the negative effects of this routine procedure. Some studies say that discomfort will affect heart rhythm, cortisol levels, crying behavior, decreased oxygen, and increased motor skills [3]. According to anatomical studies, nociceptors receiving pain stimuli in neonates have the same or even denser density than adults [4]. Neonates experience more intense pain than in older children and adults. Pain transmission in neonates is provided by $\mathrm{C}$ fibers in the peripheral nerves and provides slow and unmyelinated conduction. With these fibers providing slow, uncontrolled transmission, pain transmission causes neonates 
to experience more severe pain than adults. Research has shown that pain is felt from intrauterine life. In a study in the literature, it was found that the infant's ability to respond to pain develops during the 20th and 24th weeks of gestation during intrauterine life. [5].

Pain is also at risk for long-term adverse effects on the behavior and development of the neonate [6]. Physiological effects in response to painful stimuli or stress in the neonate result in increased circulating catecholamine levels, increased heart rate, blood pressure and intracranial pressure. [6].

Neonates underwent venous blood sampling for screening purposes during their hospital stay. Moreover, when hospitalized in the intensive care unit, painful procedures are more frequently performed, including about 16 venipunctures per day [7]. More than $90 \%$ of neonates who are hospitalized undergo invasive procedures such as venous blood collection [8]. The results of data at the University of Muhammadiyah Malang Hospital in 2017, from a total of 115 neonates, 93\% were taken for venous blood collection, at least once and a maximum of 6 times during hospitalization. The room nurse does not yet have the right action to manage the discomfort due to the venous blood sampling procedure.

The first year of research showed that the average comfort level was 22.5 where the lowest score was 5 while the highest score in patients not using a ventilator was 25 if using a ventilator, the highest score was 30 . The NIPS pain scale obtained an average result of 4.94 from the value range 1-7. The results of this study indicate that infants who are treated at the hospital experience pain when taking venous blood and experience discomfort with an average close to the maximum value.

The results of another study showed that $50.3 \%$ of neonates experienced pain and only $32 \%$ had pain management, both pharmacological and non-pharmacological [9]. This finding shows that almost $70 \%$ of neonates do not receive pain management during treatment. Recent studies have shown that controlling pain in the neonatal period is very beneficial for preventing physiological, behavioral, and hormonal complications [10]. Lots efforts are being made to prevent the long-term impact of the inconvenience of taking venous blood [1]. Olfactory stimulation [smell] to mediate pain that causes discomfort can be an alternative action [3]. The olfactory stimulation can be a long-term or shortterm memory eraser as a result of taking venous blood. Vanilla extract was chosen because its characteristics are identical to the aroma of mother's milk, which neonates are familiar with [11]. 


\section{Methods and Equipment}

\subsection{Methods}

The type of this research was descriptive analytic research. The descriptive analytical research was needed to identified and evaluated the atraumatic actions that are implemented such as blood vein collection. The research design used was a quasiexperimental post-test-only non-equivalent control group. In this design, the researcher did not randomize the distribution of respondents between the intervention group and the control group The research activities were carried out in this study had observed newborns condition that consists of identification of comfort scale levels, pain scales, changes in pulse and saturation before, during and after taking venous blood. The research place used is the Neonate Room at the General Hospital of the University of Muhammadiyah Malang.

The population in this study were all newborns who were treated in Malang and children who were treated in the Neonates Room, General Hospital, University of Muhammadiyah Malang. The sample in this study used quota sampling with limited data collection for 2 months.

The research variable in the first year is identification of comfort with a comfort scale, pain scale, pulse and saturation. The research procedure is as follows:

a] Manage licensing and ethical testing

b] Conducting research dissemination at the research site

c] Comfort scale data collection using the Comfort Scale, pain scale using the Neonate Infant Pain Scale, pulse measurement and oxygen saturation

d] Data collection was carried out 10 before taking venous blood, during and 5 minutes after taking venous blood to measure discomfort in children using the Comfort scale, which includes an assessment of the observational and physiological components in neonates who have had venous blood drawn.

\subsection{Equipment}

Neonates in hospital are routinely subjected to invasive procedures that are often painful or at least stressful. However, neonates to date have not been thought to be able to interpret pain in a similar way to adults. To date, it is clear that [i] in neonates the neuroanatomical components and neuroendocrine system are sufficiently developed to allow transmission of painful stimuli [1], [ii] lack of behavioral responses [e.g. crying] 
does not necessarily indicate a lack of pain [2] and [iii] ] several studies have shown that repeated and prolonged exposure to pain can alter subsequent psychokinetic development, as well as affect long-term neurodevelopmental and socio-emotional function [3]. Unfortunately, in most inpatient wards,[4].

Vanilla is known to be used as a complementary therapy because of several pharmacological effects such as antibacterial, antioxidant, antitussive, hypnotic, and relaxing effects as well as fragrance effects in aromatherapy methods. There are several studies assessing the effects of Aromatherapy with vanilla, and have found beneficial effects on behavioral disorders such as pain relief, anxiety, stress, sleep quality of patients. This suggests that olfactory stimulation with familiar scents and scents such as breast milk and amnion odor can reduce apnea with mild bradycardia and neonatal crying in pain.[11].

Comfort is a condition experienced by a person when exposed to an intervention, including direct and indirect experiences holistically including physical, psychospiritual, social, and environmental needs are met.[12]. The identification of neonates comfort level applied comfort scale, assessing 9 aspects [Alertness or alertness, Calmness or calmness, Breathing, Crying, Movement, Muscle strength]., Facial expressions, blood pressure and heart rate]. Each aspect has a number range of 1-5. The higher the number, the more severe and uncomfortable the pain will be.

The identification of the pain level of neonates using the NIPS [Neonatal Infant Pain Scale] instrument which has been adapted and available in the Indonesian version for neonates who have taken venous blood, in the perinatology room of UMM Hospital. The score on the NIPS pain scale is in the 1-7 range, and if the total score is more than 3 , the neonate is experiencing pain.

\section{Results}

Olfactory stimulation with vanilla extract in neonates using an approach that smells similar to breast milk, may have relaxing properties in neonates. Several studies have noted a reduction in spontaneous crying when newborns are smelled of amniotic fluid or other maternal scents. In a recent study, breastfed infants cried less during the recovery period when exposed to the smell of their mother's milk compared to bottle-fed infants who were exposed to formula or to control infants.

These effects may be mediated by the unique chemical nature of the mother's scent or the neonates' relationship to the maternal environment or, alternatively, the neonates' familiarity with their mother. Newborns have shown a remarkable ability to learn about 
TABLE 1: Demographic Data

\begin{tabular}{|c|c|c|}
\hline \multicolumn{2}{|c|}{ Demographics } & \multirow[t]{2}{*}{$\mathrm{n}[\%]$} \\
\hline Age & & \\
\hline 1 day & & $23[64]$ \\
\hline 2 days & & $6[16]$ \\
\hline 3 days & & 7 [20] \\
\hline \multicolumn{3}{|l|}{ Gender } \\
\hline Man & & $17[47]$ \\
\hline Woman & & 19 [53] \\
\hline Disease & Weight & \\
\hline Level & & 28 [76] \\
\hline \multicolumn{2}{|c|}{1 [umbilical cord } & 8 [24] \\
\hline infection, & PROM, & \\
\hline etc.] & & \\
\hline
\end{tabular}

various scents unrelated to the maternal context a few days after birth [1]. So, it is expected that premature babies are presented with a known odor [vanilla] during blood draw. calmer during recovery than babies who smell an unknown or odorless odor.

In this chapter, the results of data analysis and discussion will be presented which will explain the characteristics of research respondents. The implementation of activities is carried out in the following stages: Moderate to severe pain caused by taking venous blood in neonates has an impact on increasing energy requirements, so when the baby is sick it can cause a decrease in body resistance. Long-term impact can affect the growth and development of neonates.

\subsection{Sociodemographic characteristics}

Demographic characteristics of respondents at the University of Muhammadiyah Malang Hospital in the Perinatology Room, in October - November 2020, a total of 36 neonates' patients, with the following demographic characteristics:

2 [Asphyxia, AMS,

Hyperbilirubin]

The majority of respondents were 1 day old [64\%], with the majority gender distribution being female [19\%]. The most severe level of disease experienced was level 1 as many as 28 respondents with diseases such as premature rupture of membranes and umbilical cord infection.

In this study, there were more female respondents compared to male respondents, this is in accordance with Aghagoli et.all's 2016 study where this study also treated 


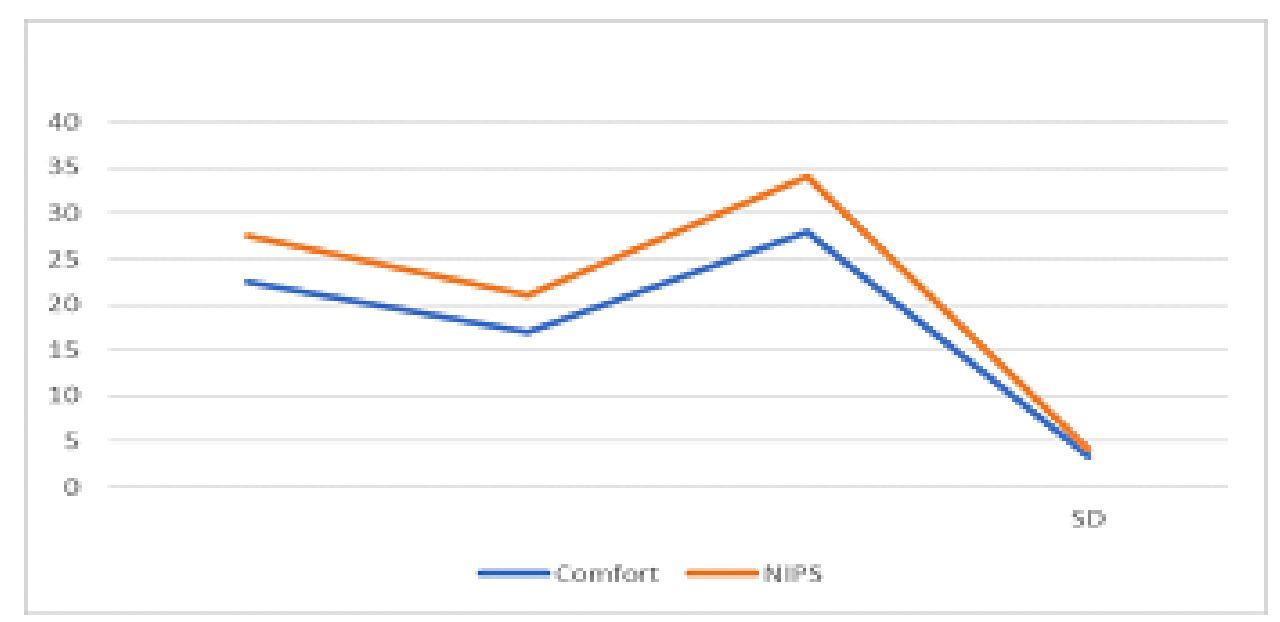

Figure 1: Pain level and Comfort Scale.

neonates with a greater number of female respondents. The majority of respondents have a level 1 disease category. Level 1 disease that is commonly found in the perinatology room is PROM [premature rupture of membranes].

\subsubsection{Identification of Comfort Scale}

The results of the identification of the pain level of neonates using the NIPS [Neonatal Infant Pain Scale] instrument which has been adapted and available in the Indonesian version for neonates who have taken venous blood, in the perinatology room of UMM Hospital, has an average value [4.94 \pm

0.71]. The score on the NIPS pain scale is in the 1-7 range, and if the total score is more than 3 , the neonate is experiencing pain. This is in line with research on the pain response of neonates at the time of taking venous blood, which has an average of 5 .

The results of the identification of the comfort level of neonates using this comfort scale, assessing 9 aspects [Alertness or alertness, Calmness or calmness, Breathing, Crying, Movement, Muscle strength]., Facial expressions, blood pressure and heart rate]. Each aspect has a number range of 1-5. The higher the number, the more severe and uncomfortable the pain will be. The results of measuring the comfort scale in neonates when taking venous blood in the perinatology room of UMM Hospital obtained an average $[22.5 \pm 3.41]$ this is in line with several studies conducted. 


\section{Conclusion}

Providing comfort to neonates during routine procedures for taking venous blood in hospitals should be an integrated nursing action management in every inpatient room. Non-pharmacological intervention protocols that do not contain side effects on both the physical and psychological aspects of neonates in inpatient wards are very important to implement, but the study results found related to this study are still very limited and require further study. \{Formatting Citation $\}$.

Olfactory stimulation with vanilla extract was chosen because it has a characteristic like breast milk which has a significant calming effect on neonates during the procedure, especially in infants who are not exclusively breastfed. A good research design still requires further research, in order to achieve optimal results, such as determining the level of vanilla extract used in a few drops, the time interval between the vanilla administration procedure and the venous blood collection, and the distance between the last breastfeeding and the venous blood sampling procedure.[14].

The intervention that must be applied within the scope of pediatric nursing is the principle of atraumatic care where the provision of care is sought to provide a sense of comfort to the neonate[10].

\section{Funding}

This work was supported by Basic Scientific Research that fully funded by DPPMUniversity of Muhammadiyah Malang term 2020.

\section{Acknowledgement}

The authors would like to thank University of Muhammadiyah Malang Hospital for the contribution and support to this research. They are also thankful to all the reviewers who gave their valuable inputs to the manuscript and helped in completing the paper.s

\section{Conflict of Interest}

The authors have no conflict of interest to declare. 


\section{References}

[1] . Neshat H, Jebreili M, Seyyedrasouli A, Ghojazade M, Hosseini MB, Hamishehkar $\mathrm{H}$. Effects of breast milk and vanilla odors on premature neonate's heart rate and blood oxygen saturation during and after venipuncture. Pediatrics \& Neonatology. 2016;57(3):225-31. http://dx.doi.org/10.1016/j.pedneo.2015.09.004

[2] . Khalid K, Ramli N, Nasir A, Rostenberghe H. A randomized controlled trial comparing the effects of honey versus sucrose as analgesia during venipuncture in the newborns a randomized controlled trial comparing the effects of honey versus sucrose as analgesia during venipuncture in the newborns. International Medical Journal. 2019; 26(6), 460-463.

[3] . Goubet N, Lequien P. Olfactory experience mediates response to pain in preterm newborns. Developmental Psychobiology: The Journal of the International Society for Developmental Psychobiology. 2000; 42(2), 171-180.

[4] . Bouza H. The impact of pain in the immature brain. The Journal of Maternal-Fetal \& Neonatal Medicine. 2009;22(9):722-732.

[5]. Cirik VA, Aksoy B. Painful procedures experienced by preterm newborns and evidence-based non-pharmacological methods. International Journal of Emerging Trends in Health Sciences. 2020; 4(1), 27-35.

[6]. Taksande AM, Vilhekar KY, Jain M, Chitre D. Pain response of neonates to venipuncture. The Indian Journal of Pediatrics. 2005;72(9):751-3.

[7] . Bellieni C V., Stazzoni G, Tei M, et al. How painful is a heelprick or a venipuncture in a newborn? The Journal of Maternal-Fetal \& Neonatal Medicine. 2016;29(2):202-6. http://dx.doi.org/10.3109/14767058.2014.992334

[8] . Azarmnejad E, Sarhangi F, Javadi M, Rejeh N, Amirsalari S, Tadrisi SD. The effectiveness of familiar auditory stimulus on hospitalized neonates' physiologic responses to procedural pain. International journal of nursing practice. 2017;23(3):17.

[9] . Sposito, N. P. B., Rossato, L. M., Bueno, M., Kimura, A. F., Costa, T., \& Guedes, D. M. B. Assessment and management of pain in newborns hospitalized in a neonatal intensive care unit: A cross-sectional study. Revista latino-americana de enfermagem. 2017;25.

[10]. Witt N, Coynor S, Edwards C, Bradshaw H. A guide to pain assessment and management in the neonate. Current emergency and hospital medicine reports. 2016;4(1):1-10. 
[11]. Aghagoli S, Salimi A, Salimi M, Ghazavi Z, Marofi M, Mohammadbeigi A. Aromatherapy with Rosa damascenes in apnea, bradycardia and Spo2 of preterm infants; A randomized clinical trial. International Journal of Pediatrics. 2016;4(6):19118.

[12] . Rn KMSN, Nursmg A, Is C. An analysis of the concept of comfort. 1991:1301-10.

[13] . Filippa, M., Poisbeau, P., Mairesse, J., Monaci, M. G., Baud, O., Hüppi, P., ... \& Kuhn, P. Pain, parental involvement, and oxytocin in the neonatal intensive care unit. Frontiers in psychology. 2019;1-15, 10, 715.

[14] . Wei YC, Tsao PN. Effects of breast milk and vanilla odors on premature neonates' heart rate and blood oxygen saturation during and after venipuncture. Pediatrics and Neonatology. 2016, 57(6), 548. 